\title{
On the Development of Web-based Distance Physical Education
}

\author{
Shaohui Yuan, Chao Wang, and Yunna Zhao \\ Hebei Vocational \& Technical College of Building Materials, 066004 Qinhuangdao Hebei, China
}

\begin{abstract}
With the progress and development of the society, sports cause and sports industry have attracted more and more attention. The traditional physical education pattern can no longer satisfy the needs of people from all walks of life. The development of the Internet provides a huge space for web-based distance physical education. The characteristics of physical education provides great potential for the development of the web-based distance physical education, however, there still exists some problems concerning it. By making surveys, reading relevant documents, interviewing experts and by logically reasoning, the author analyzed the development of web-based distance physical education and then drew the following conclusions: First, further optimize the Internet environment; second, establish and adjust the current teaching curriculum; finally, design reasonable teaching procedures.
\end{abstract}

Keywords. web-based education; distant education; development of physical education

\section{Background}

The modern society has entered the era of information, the era of knowledge economy and the era of network. And the Internet has exerted great influence on people's daily life. The development of education plays an important role in the progress of a nation. Under these circumstances, education must meet the needs of social development and people's learning, and make full use of high technology to serve the education. This has become a tendency of modern education. Modern distance education is on its third stage characterized by the network. China's online education started with the implementation of China Education and Research Network Demonstration Project in 1994, which has developed to some extent. In the field of higher education, the Ministry of Education authorized Tsinghua University and other five universities to conduct an experimental work on online universities since 1998. After that, in 2000, the thirty universities that have set up their graduate schools were also approved to carry out web-based distance education with the purpose of granting junior college degree and bachelor's degree, or offering graduate courses. However, the research of modern distance education in physical education (PE for short) was just started in 2000 and it was developed slowly. With the rapid popularization of PE industry and the potential 
economic prospect it may bring, after the 2008 Beijing Olympic Games, the PE is gradually becoming popular and people's demands on PE and other related fields are quickly going up. Meanwhile, because of the college expansion plan in 1999, the number of students at colleges and universities skyrockets and it is almost close to saturation. Thus the existing $\mathrm{PE}$ teaching conditions can no longer satisfy the learning requirements of more people from different social classes. Under these conditions, the existing PE pattern is far from satisfying the needs of the modern society. As a result, it is highly necessary to carry out modern PE distance education characterized by the network.

\section{Prospect of web-based distance education offered by the rap- id development of PE in China}

\subsection{The development of PE industry}

As a new industry, the annual revenue of global sports industry has reached $\$ 450$ billion with the average annual growth rate of 20 percent. In such developed countries as the United States and Japan, the output value of sports industry has surpassed those industries like petrochemistry and automobile whereas sports industry in China started late and the scale is relatively small. But with the progress of the society, there is no doubt that as a sunrise industry, China's sports industry will hold great prospect for further development. Therefore, people's demands on education related to sports industry is increasing in order to fulfill the needs of social development and serve the society better. A great number of professional staff are urgently needed for the development of sports industry, especially sports fitness markets, competition show business markets, sports goods markets, sports intermediary markets, and sports lottery business. More professional, formal training and reeducation are necessary for the staff in each market.

\subsection{The status quo of the training of college sports talents}

After over forty years' hard work and development, PE departments in China's colleges and universities have laid a sound foundation with a certain size. According to incomplete statistics by 2000, there are 75 PE departments in normal universities, 234 PE departments in colleges and $16 \mathrm{PE}$ institutes. In the past, there were only such majors as physical education and sports training, but now more majors have been added, such as sports science, sports management, traditional national sports, and social sports and so on. At the same time, the college expansion plan in 1999 results in both the rapid increase of the number of students majoring in PE and the adjustment of some majors. Thus, the present scale and teaching conditions in PE departments can no longer satisfy students' various demands. So by learning from the successful experience in other majors, PE departments should also carry out web-based education because it can meet the demands of more students and provide them with more chances to learn professional sports knowledge.

\subsection{The increase of people's demands on sports}

With the rise of people's living standards, their spiritual cultural life becomes richer and richer. Meanwhile, the ideology of "Health first" and "Lifelong education" has deeply rooted in people's mind and more and more people take part in fitness and entertainment. Therefore, people pay more attention to the principle, knowledge and methods of fitness and they understand the fitness programs they are engaged in are from a more professional perspective. In addition, the booming sports show business in the whole society makes 
more people go to the fitness centers and hope to be more professional in fitness and entertainment. They want to improve not only their ability to appreciate but also their athletic performance. Web-based distance physical education can offer help to more ordinary people and satisfy the needs of people from all phases of life as well as the needs of people engaged in sports.

\section{Web-based distance physical education}

By investigating the status quo of the current distant education of PE, the authors find there are still some problems which are needed to deal with. The distant education of PE will never play its full role if these problems cannot be solved. And the status quo of web-based distant education is elaborated from four aspects as follows.

\subsection{Educational subjects}

The educational subjects include students at colleges and universities, ordinary people who love sports and cherish their health, and those professional sports staff such as researchers, administrators, PE teachers, coaches, social sports instructors, theorists and sports health staff.

The existing educational system includes academic education and non-academic education. Academic education refers to full-time college-level education, undergraduate education, master's degree education and doctorate degree education. And non-academic education means skill training, qualification authentication, seminars and so on.

The popular teaching method used in full-time PE academic education is the traditional face-to-face way. This method adopts the class-based teaching system and makes students study in the same environment. It really makes a great difference to PE teaching, however, because of the limited objective conditions, only a small number of students are educated, whereas the rise of web-based education, that is, making full use of online schools, can satisfy the academic needs of people from different regions. The non-academic education of part-time learners is a recharging process for working staff. Compared with full-time education, part-time education cannot provide more class hours and there isn't much communication between teachers and students, or among students. Besides, because of the pressure from both work and family, part-time learners don't have fixed time for study. As a result, teaching is of low quality, learning is not systematic and transportation expenses increase the learning cost. This is especially the case for higher degree education, say, master's degree education. The common forms of the reeducation of master's degree of PE are equivalent education, training courses for university teachers and master's degree of PE. The curriculum of those teaching forms is centered on the teaching of theories, but skills and technology are seldom involved. Therefore, web-based education is especially suitable for the education of master's degree of PE since it can help sports staff properly arrange their time for study and can satisfy their needs in a human-centered way.

Skill training and other forms in non-academic education can give full play to the advantage of web-based distance education, which breaks the limitation of regions, time and space, and can satisfy the needs of the training on more people including social sports instructors, community service workers, coaches and the staff in all kinds of sports and fitness entertainment places. The trainees can use the Internet to study the same things repeatedly, memorize them, improve the professional competence and fulfill the purpose of training.

\subsection{The features of PE teaching}


PE teaching has its own features. It is composed of theoretical teaching and technology teaching. Since the teaching method of theoretical teaching is the same as that of other disciplines, it is feasible to learn from other disciplines on how to use web-based distance education. By doing so, the teaching objectives can be better completed. But technology teaching is quite different. Teachers not only need to demonstrate but also need to correct and comment on students' techniques in order to make them internalized and stereotyped.

\subsection{The characteristics of web-based distance PE education}

Web-based distance PE education has the characteristics of wide coverage, it can comprehensively provide people from all social classes with new learning opportunities and it is characterized by serving the autonomous learning. What's more, web-based distance PE education makes PE teaching separate teaching from learning in the dimensions of time and space, and then reintegrates teaching with learning, quickly updates teaching contents, shares resources and gives learners more freedom to choose their majors. More importantly, web-based distance PE education can make PE teaching become visualization. Video teaching can help learners master technical movements, correct wrong movements and explain the reasons of wrong movements. For learners, by repeatedly watching the video clips and by imitating, they can design their own learning process so as to comprehend and fulfill the teaching objectives quickly and accurately.

\subsection{Problems in web-based distance PE education}

Distance education breaks the restriction of location and time on the popularity of education. Ultimately, the new teaching objective is the fulfillment and development of mass education in modern environment. The modern distance education characterized by the network is to optimize the closed traditional teaching mode. It takes the traditional PE teaching a great amount of time to carry out class teaching on a small scale. This mode of high consumption and low efficiency with the limitation of time and space will be changed by distance education. Because the unique features of PE teaching, continual communication between teachers and students is really necessary. This communication is conducted not only by oral language but also by body language. Teachers can offer students great help by using a gesture and a body contact, which cannot be completed in web-based teaching. However, with the progress of science and technology, those problems can be solved step by step.

\section{Developing strategies of web-based distance PE education}

Based on the analysis of the status quo of web-based distance education, some improvements should be made to make the distance education come to its full play.

\subsection{Setting the curriculum to meet the needs of different learners}

Education emphasizes teaching students in accordance with their aptitude. Therefore, webbased education should set appropriate curriculum to meet the needs of different academic teaching objectives as well as non-academic education. Academic education should highlight systematicness, completeness and comprehensiveness, adopt a credit system, simplify the required courses, enlarge the scale of selective courses and make full use of the advantages of online resources. Only if students have the freedom of choosing their own way of development can they enhance their interest in learning and consequently the 
teaching objectives can be fulfilled. As for non-academic education, the teaching objectives are different. Its curriculum should be accordingly adjusted to help learners get more practice and solve their practical problems. The video clips on the Internet demonstrated by sports stars can not only arouse ordinary people's interest but also gratify their learning demands on competitive sports.

\subsection{Drawing on the merits of other disciplines}

With the development of PE, it covers more and more contents and overlaps other disciplines. The web-based distance PE education started late and is not mature. In terms of theoretical teaching, the teaching contents, the successful and effective web-based teaching experience which other disciplines have obtained can surely provide support and help for web-based distance PE education. In the course of teaching, the knowledge of the parent discipline of some disciplines can be used as part of the contents of PE teaching. In the meantime, the advanced teaching patterns and methods of those first disciplines which carried out web-based education can provide web-based distance PE education with favorable supports. Technological lessons are one of the unique features of PE. Although web-based education provides more convenience for skill teaching and video clips, emails and chat rooms have also greatly improved teaching effectiveness, and body-assisted teaching has not been realized on the Internet. However, web-based piano teaching throws light on us. Through continuously perfecting web-based teaching environment, updating and improving web-based teaching system and teaching students in accordance with their aptitude, we believe the effectiveness of web-based teaching will be better in the near future.

\subsection{Designing a scientific web-based teaching environment}

The effect of web-based teaching has direct influence on the development and future of web-based education especially on such distinctive disciplines as PE. Hence, it is very necessary to increase the investment in scientific research, to have a better understanding of the authentic environment for PE education, to design advanced scientific program and to establish a web-based teaching system. At the same time, only by strictly controlling teaching and by standardizing online testing modes can qualified people be cultivated. Even though there are still some problems with the designing and the testing of PE skill teaching, we believe, in the near future, they can be brought to a satisfactory settlement through our joint efforts.

\section{Conclusion}

With the rapid development of modern science and technology, the computer network technology has penetrated every corner of the society. The modern Internet-based distance education has greatly changed people's concept of education. The traditional PE teaching mode can neither satisfy the development of PE in China nor fit in with the development of present distance education. What we need to do is to improve the teaching pattern and form a new teaching mode through the introduction of modern web-based teaching technology. By using the powerful link function of the Internet, setting up PE educational websites of all levels and fulfilling web-based distance teaching, we can better eliminate the weaknesses of the traditional PE mode, save teaching costs, make full use of the advantages of online resources, improve the teaching quality, satisfy the needs of more and more people on lifelong sports and ultimately better serve the society. 


\section{References}

1. Liang Jian. 2001. On the development of web-based education. Journal of the Chinese Society of Education, (2): 41-44.

2. Hu Aiben. 2004. Introduction on Sports Management. Beijing: Higher Education Press.

3. Lu Zunyi. 2000. Research on the joint running pattern by pe departments in normal universities. Sports Science, 20(1): 10.

4. He Qiuhua, \& Zhou Wei. 2003. Establishment and accomplishment of PE distant education system. Journal of Guangzhou Physical Education Institute, (6): 109-111.

5. Wu Hao, Hu Xiaoming, \& Tan Hua etc. 2001. Developing China's distance PE education. Journal of Physical Education, (2): 8-10.

6. Xiong Douyin. 2001. The era of network and physical education. Sports and Science, 22(2): $1-7$. 